\title{
OVERTIME WORK, DUAL JOB HOLDING, AND TAXATION
}

\author{
Anders Frederiksen, Ebbe Krogh Graversen and \\ Nina Smith
}

\begin{abstract}
Labor supply data seldom include detailed information on hours and wages in secondary job or overtime work. Based on survey information on hours and wages in overtime work and second job which is merged to administrative register information on income taxes and deductions we estimate a "Hausman labor supply model," which allows for a detailed treatment of nonconvexities. Including explicit information on overtime pay and second job wages increase the estimated elasticities compared to a standard labor supply model without this information. However, allowing a more flexible treatment of nonconvexities the estimated elasticities are reduced; even below the estimates of the baseline results. In simulations we show that these findings have significant consequences when evaluating the degree of self-financing of various tax reforms.
\end{abstract}

\section{INTRODUCTION}

A major criticism of many labor supply models is that hours cannot be varied freely within jobs and that the decision to work overtime or to enter a

\footnotetext{
Work, Earnings and other Aspects of the Employment Relation

Research in Labor Economics, Volume 28, 25-55

Copyright (C) 2008 by Emerald Group Publishing Limited

All rights of reproduction in any form reserved

ISSN: 0147-9121/doi:10.1016/S0147-9121(08)28002-7
} 
second job is different from the work hours decision in the main occupation. ${ }^{1}$ In general, overtime wages exceed the wages in main occupation and second jobs typically imply additional fixed costs of work. The purpose of this paper is to examine the role overtime work and duel job holding plays for the labor supply decision of men and women. The use of additional information on overtime and second job gives a more flexible and realistic modeling of the actual labor supply.

The explicit modeling of fixed costs of work, overtime payments, and wages in second jobs is expected to be very important when analyzing potential tax reforms. The main reason is that tax reforms that changes the marginal income tax rates potentially changes the budget segment where the individual's optimal labor supply is positioned. In particular, a tax reform with tax cuts increases the individual's incentives to work overtime or take a second job. Thus, it is important that the estimated model takes the nonlinearities of the budget constraint related to this decision into account.

Despite the vast literature on labor supply models, there are relatively few studies focusing on the implications of overtime work and dual job holding (cf. Hart, 2004). One of the first studies, which explicitly model these aspects of the supply decision, is Ashworth and Ulph (1981). They find numerically larger elasticities when overtime and second job wages are explicitly modeled compared to a model where the budget constraint is linearized around the point of observation.

In this paper, we apply a piecewise linear approach, for simplicity denoted a "Hausman approach," which allows for an explicit treatment of the nonlinearities imposed by the tax system. This approach is known to be sensitive to the specification of functional forms and measurement errors in the hours and wage variables. In addition, the Hausman model is very demanding with respect to the information required to construct the budget constraint (see, for instance, Blundell \& MaCurdy, 1999). Introducing information on overtime work and dual job holding requires two extensions of the traditional Hausman approach. First, the number of budget segments is increased to capture variation in wages between main job, overtime work, and second job. Second, we anticipate that some workers will have additional costs associated with working in a second job. The extensions are found to be empirically relevant for both men and women.

The estimated model is a generalization of a Tobit model that accounts for the joint participation and hours decision which is especially important when we look at female labor supply where a significant part of the women are nonparticipants. ${ }^{2}$ In addition, we take measurement errors in the labor supply as well as unobserved heterogeneity in preferences into account. 
The model is estimated on a survey collected by Statistics Denmark in 1996. The survey information is merged with very detailed information from administrative registers on incomes and taxes. The main feature of the data which is explored extensively in this paper is the detailed information on individual labor supply and wages in a person's main job, overtime work, and second job. Our results show that the labor supply elasticities are highly sensitive to the inclusion of the information on overtime work and secondary job and to the handling of fixed costs of work. The additional information increases the estimated elasticities as in Ashworth and Ulph (1981). However, the subsequent introduction of flexibility reduces the estimated elasticities considerably compared to traditional labor supply models without explicit information on overtime pay and second job wages. Hence, our new results show that omitting crucial information related to work hours exceeding the hours in the main job may lead to significant overestimates of the labor supply effects and the degree of self-financing of tax reforms. The economic consequences of this shortcoming may be large.

The theoretical framework is discussed in the next section. In Section 3 we present the data and show descriptive statistics. The choice of empirical model is motivated in Section 4. We give a detailed discussion of the models assumptions and propose various empirical model specifications in Section 5. The results from the estimations are presented in Section 6. These results are used for simulation of four hypothetical tax reforms in Section 7. Finally, Section 8 concludes the paper.

\section{THE THEORETICAL MODEL}

We model the individual labor supply decision using a piecewise linear approach which is known as the Hausman model. ${ }^{3}$ The individuals choose bunches of consumption and hours of work, $(C, h)$, which maximizes their utility function $U(C, h)$, given the piecewise linear budget constraint. The constrained utility maximization implies a labor supply function, which depends on the after-tax wage rate and after-tax income.

The traditional Hausman model relies on the assumption that workers face one exogenously given wage rate which is independent of the number of hours supplied. Embedded in this approach is that the individual can vary the number of hours freely at a given wage rate ignoring all institutional settings in the market such as labor laws requiring overtime compensation and limits to the number of hours an individual can supply in a given job. Since these restrictions are important in labor markets, we extend the 
conventional model and explicitly integrate information on overtime and second job into the individual-specific budget constraint. This means that instead of one wage, individuals are now facing three exogenous wage rates in the market; i.e., a wage in the main job, an overtime wage, and a second job wage. ${ }^{4}$ This results in the following budget constraint:

$$
C=\left(w^{\mathrm{m}} h^{\mathrm{m}}-\mathrm{FC}^{\mathrm{m}}\right)+w^{\mathrm{o}} h^{\mathrm{o}}+w^{\mathrm{s}} h^{\mathrm{s}}+Y+V-t(I)
$$

where $C$ is annual consumption, $w^{\mathrm{m}}, w^{\mathrm{o}}$, and $w^{\mathrm{s}}$ are the hourly wage rates in main occupation, overtime work, and second job, respectively, $h^{\mathrm{m}}, h^{\mathrm{o}}$, and $h^{\mathrm{s}}$, annual labor supply in main occupation, overtime work, and second job. $Y$ is annual taxable nonlabor income, $V$, annual nontaxable nonlabor income, including spouse's after-tax income if married or cohabiting. $t(I)$ is the tax function, where $I$ is annual assessed income, $I=\Sigma w h+Y-D$, and $D$ is annual deduction. $\mathrm{FC}^{\mathrm{m}}$ are the fixed money costs of work, e.g., costs of transport and childcare, associated with the job.

We consider two specifications for hours. ${ }^{5}$ First, we apply the "hours constraints" specification outlined in Shisko and Rostker (1976) who assume that hours supplied to different types of jobs have similar disutility, i.e., $h=h^{\mathrm{m}}+h^{\mathrm{o}}+h^{\mathrm{s}}$. Further, hours constraints and institutional factors in the main occupation is the primary motivation for multiple job holding. Second, we use the "heterogeneous-job" specification discussed in Conway and Kimmel (1998) and Heineck and Schwarze (2004) and explore how variation in the nonpecuniary benefits or unobservable costs associated with different jobs can account for the observed variation in hours. This is implemented by allowing the disutility of work between the main employer (main hours and overtime hours) and work in a second job to differ in the econometric specification. Because these costs are nonmonetary, they do not show up in Eq. (1).

The nonlinear budget constraint is characterized by its kinks, the after-tax wage rates and virtual incomes on the linear segments. These can be obtained using a simple iterative procedure as long as nonlabor income, gross wage rates, labor supply, and the tax system are known. Fig. 1 exemplifies a budget constraint for a person who has both overtime work and a second job in addition to the main occupation. The person was subject to the Danish tax system in 1996 which had four tax segments and three kink points. The marginal tax rates on the four segments were $7 \%$, $47.2 \%, 51.8 \%$, and $65.8 \%$ and the distribution of individuals in the sample is shown in Table 1 for men and women, separately. In general, the marginal tax rates in Denmark are high compared to most other OECD countries 


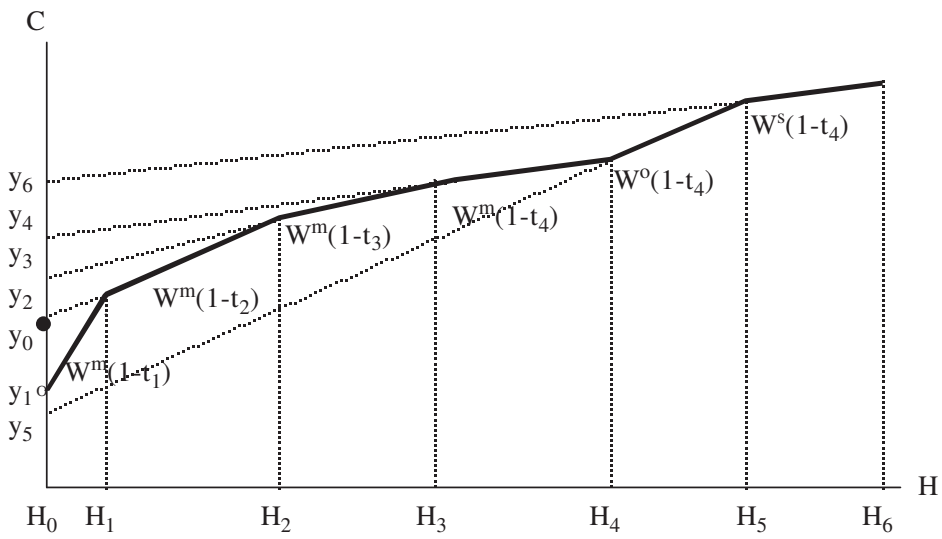

Fig. 1. The Piecewise Linear Budget Constraint with Fixed Costs of Work and Six Linear Segments due to Nonlinear Income Taxes and Different Wages in Main Occupation, Overtime Work, and Second Job. Note: The difference between $y_{1}$ and $y_{0}$ in Fig. 1 is the sum of fixed costs of work and reductions in unemployment or social welfare benefit. It is assumed that the unemployment and social welfare benefit disappears when the first hours is worked in accordance with the rules in Denmark in 1996.

Table 1. Distribution of Men and Women by Marginal Tax Rates.

\begin{tabular}{lccccc}
\hline & $\begin{array}{c}\text { Marginal Tax } \\
\text { Rate } \leq 7 \%\end{array}$ & $\begin{array}{c}\text { Marginal Tax } \\
\text { Rate 47.2\% }\end{array}$ & $\begin{array}{c}\text { Marginal Tax } \\
\text { Rate 51.8\% }\end{array}$ & $\begin{array}{c}\text { Marginal Tax } \\
\text { Rate 65.8\% }\end{array}$ & All (\%) \\
\hline Men & $1 \%$ & $10 \%$ & $58 \%$ & $31 \%$ & 100 \\
Women & $3 \%$ & $34 \%$ & $54 \%$ & $9 \%$ & 100 \\
All & $2 \%$ & $23 \%$ & $56 \%$ & $19 \%$ & 100 \\
\hline
\end{tabular}

(see, for instance, OECD, 1996) and the actual marginal tax rates are considerably higher for men than for women. This reflects the higher level of earnings and nonwage income of men, but it also reflects the Danish tax system which is dominated by a separate taxation of spouses (see Smith, Dex, Vlasblom, \& Callan, 2003).

Labor supply up to $\mathrm{H}_{4}$ in Fig. 1 represents work in main occupation, excluding overtime work, with an hourly gross wage rate, $w^{\mathrm{m}}$. The person is assumed to have an income in main occupation, excluding overtime work, which passes the three thresholds or kinks of the progressive income tax 
scheme. If the person works more than standard hours, he is assumed to get an overtime compensation, which exceeds the standard wage in the main occupation. This is represented by the hours range from $H_{4}$ to $H_{5}$. Further, the person may have a second job. In Fig. 1, it is assumed that the net wage in second job equals the hourly main job wages.

A different budget constraint arises if the person has a relatively low hourly wage rate in main occupation - or a very large tax deduction - which implies that kink points from the tax schedule may lie in the hour ranges for overtime work or second job. There are of course a number of possible combinations of hypothetical budget constraints, depending on the size of $Y, V, D$, the wage rates and the job opportunities faced by the individual.

The after-tax wage rate on segment $j$ is given as $w_{j}^{i}=w^{i}\left(1-t_{j}\right)$ where $t_{j}$ is the marginal tax rate on segment $j$, and $w^{i}$ is the hourly wage rate in either main occupation, overtime work, or second job $(i=m, s, o)$. To simplify notation, we drop the subscript $i$ in the following. The virtual income on the first budget segment is given as $y_{1}=V+Y-t(Y-D)-\mathrm{FC}^{\mathrm{m}}$. The virtual income corresponding to segment $j$ can be found iteratively as $y_{j}=y_{j-1}+\left(w_{j-1}-w_{j}\right) H_{j-1}, \forall j \geq 2$.

Given the definition of $y_{j}, w_{j}$, and $H_{j}$ above, the individual's optimization problem becomes the following, where $k$ is the maximum number of segments $(k=6$ in Fig. 1).

$$
C= \begin{cases} & \operatorname{Max} U(C, h) \\ y_{1} & \text { if } h=H_{0} \\ w_{j} h+y_{j} & \text { if } H_{j-1}<h<H_{j} \quad j=1, \ldots, k \\ w_{k} H_{k}+y_{k} & \text { if } h=H_{k}\end{cases}
$$

$H_{k}$ corresponds to the total time allocation. The solution to the maximization problem is obtained from an algorithm that compares all local optima for the complete budget constraint and returns the global optimum, which is the maximum of all local optimal utilities. The first step of the algorithm is to identify the locally optimal choice of labor supply from the desired hours function, $f\left(w_{j}, y_{j}\right)$, for each linear segment of the budget constraint. If the locally optimal solution is calculated to be within the range of hours over which the linear segment is defined, it is said to be "feasible." If we have a "convex" kink and the locally optimal solution on a segment lies above the feasible range and if the locally optimal solution on the following segment lies below the feasible range, we have a kink between two segments as a feasible solution. An interior "nonconvex" kink can never 
be a feasible solution (while the corner solution at $h=0$ may be both optimal and feasible). Hence, this first step yields a vector of information about the segments and kinks where an element takes the value one if the segment is feasible and zero otherwise. Second, after all feasible local optima have been identified, the algorithm finds the global optimum by calculating which is the feasible local optima that generates the maximum utility.

When the direct utility function is only implicitly available, the maximum must be calculated using the indirect utility function. It is easily done for all the feasible segments, but no definitive wage rate exists at the kink points. However, we can evaluate the inverse demand function, $w=w(h, y)$, at the hours corresponding to the kink point and find a "support" wage rate and virtual income. By duality, the substitution of the "support" wage rate and income into the indirect utility function at the kink point hours is sufficient to evaluate the level of direct utility at the kink point (cf. Duncan, 1993).

\section{DATA}

The data used in this study are based on a survey of 4,000 Danes collected by Statistics Denmark in 1996. The initial sample covers the age range of 16-74 years. In the present study we restricted the sample to individuals aged 18-59 years to limit the influenced of human capital accumulation and retirement (early retirement schemes are available from age 60). We include married, cohabiting, as well as single individuals in the sample, but exclude individuals with long-term illness, students, self-employed persons, and their spouses. The exclusion of the two latter groups is made because we are unable to calculate their income taxes and hence to construct their budget constraints because the Danish tax rules for self-employed families requires more information than is available in the database. The exclusions result in a sample of 2,441 individuals.

The labor supply of unemployed individuals is determined by questions on their search behavior. Unemployed individuals who are on unemployment insurance benefits or social welfare are asked the conventional questions from labor force surveys on search behavior. Based on the answers to these questions, we divide the unemployed into two groups, those who satisfy the ILO conditions of being unemployed (involuntarily unemployed) and those who do not (voluntarily unemployed). The ILO criteria for being categorized as (involuntarily) unemployed are that the person has been seeking for a job actively within the latest month and that 
he or she is able and willing to start in a new job within the next two weeks. If the person satisfies these conditions, he or she is assumed to have a desired labor supply of $37 \mathrm{~h}$ weekly if full-time insured against unemployment and $20 \mathrm{~h}$ weekly if part-time insured against unemployment. ${ }^{6}$ If the person does not satisfy the ILO criteria, he is categorized as voluntarily unemployed with a desired labor supply of $0 \mathrm{~h}$. Euwals and van Soest (1999) and Bingley and Walker (2001) have applied a similar identification procedure using data for the Netherlands and the UK, respectively.

The sample includes survey information on weekly normal hours in main occupation, normal working hours in second job, if the person holds a second job, and number of hours in overtime work in the week prior to the survey week. ${ }^{7}$ Tables 2 and 3 show the distribution on employment states and average weekly hours in main job, overtime work, and second job for the 1,150 men and 1,291 women included in the empirical sample. The majority of the sample has only a main job. More men than women tend to work overtime or have a second job, and a higher proportion of women are nonparticipants. Twelve percent of the individuals in the sample are either unemployed or observed as nonparticipants, $64 \%$ have only one job and no overtime hours, and $24 \%$ have a second job or work overtime beside their main occupation. Out of these $24 \%, 18 \%$ - points only work overtime, $5 \%$ - points only have a second job, while a little more than $1 \%$ - point is observed to have overtime hours as well as a second job. ${ }^{8}$ The weekly number of working hours is relatively low in Denmark compared to other European countries. On average, an employed man works more than an employed woman in all three job types: main job, overtime, or second job (cf. Table 3).

Table 2. Distribution of Men and Women in Nonparticipation, Unemployment, and Employment in Main, Overtime, and Second Job Occupation.

\begin{tabular}{llllllll}
\hline Nonparticipants & Unemployed & $\begin{array}{c}\text { Main } \\
\text { Occupation } \\
\text { Only }\end{array}$ & $\begin{array}{c}\text { Main and } \\
\text { Overtime }^{\mathrm{a}} \\
\text { Occupation }\end{array}$ & $\begin{array}{c}\text { Main and } \\
\text { Second Job } \\
\text { Occupation }\end{array}$ & $\begin{array}{c}\text { Main, } \\
\text { Overtime } \text { Second Job }^{\text {Send }} \\
\text { Occupation }\end{array}$ & Total \\
\hline Men & $0.03(36)$ & $0.06(72)$ & $0.60(694)$ & $0.22(254)$ & $0.06(72)$ & $0.02(22)$ & $0.99(1,150)$ \\
Women & $0.08(101)$ & $0.07(86)$ & $0.67(864)$ & $0.14(187)$ & $0.03(45)$ & $0.01(8)$ & $1.00(1,291)$ \\
All & $0.06(137)$ & $0.06(158)$ & $0.64(1,558)$ & $0.18(441)$ & $0.05(117)$ & $0.01(30)$ & $1.00(2,441)$ \\
\hline
\end{tabular}

Note: Number of observations in parentheses.

${ }^{\mathrm{a}} 130$ men and 81 women with observed overtime (main hours exceeding 37 per week) did not get any compensation for their overtime work. These observations are included in Column 3 (Main Occupation Only). 
Table 3. Average Weekly Hours in Main Occupation, Overtime, and Second Job, Conditional on Participation.

\begin{tabular}{lcccc}
\hline & Main Occupation (h) & Overtime Work (h) & Second Job (h) & Total (h) \\
\hline Men & 37.9 & 2.1 & 1.0 & 41.0 \\
Women & 34.5 & 1.0 & 0.4 & 35.9 \\
All & 36.1 & 1.5 & 0.7 & 38.3 \\
\hline
\end{tabular}

Table 4. Observed Average Hourly Wages in Main Occupation, Overtime Work, and Second Job.

\begin{tabular}{|c|c|c|c|c|c|c|}
\hline & \multicolumn{2}{|c|}{ Main Occupation } & \multicolumn{2}{|c|}{ Overtime Work } & \multicolumn{2}{|c|}{ Second Job } \\
\hline & $N$ & Wage, DKK & $N$ & Wage, DKK & $N$ & Wage, DKK \\
\hline Men & 1,042 & 133.7 & 276 & 170.1 & 94 & 140.5 \\
\hline Women & 1,104 & 107.0 & 195 & 148.6 & 53 & 135.9 \\
\hline
\end{tabular}

In the survey we have detailed information on individual wages in each of the three job types: main job, overtime, and second job. Hence, we know for instance if a person working overtime is compensated beyond his main job wage. The compensation or extra payment for overtime work is determined by union-specific collective agreements with Danish employers. Standard working hours is $37 \mathrm{~h}$ per week and additional work taking place at the main employer is considered overtime work. Hourly or weekly paid manual workers typically get overtime payments or they are allowed to take time off later on. Monthly paid nonmanual workers seldom get overtime pay. In some cases, they may have the right to take time off later on (see Smith, 1998).

The sample values of average observed wage rates (conditional on participation) in main occupation, overtime work, and second job are shown in Table 4. Overtime payments exceed the payments for standard hours in main occupation and second job with a considerable amount, while second job wages on average are higher than main job wages but lower than hourly overtime payments. More detailed cross tabulations show that individuals with low hours in main occupation tend to have relatively low hourly wages in second job, while individuals with a full-time job have higher wages in a second job (see Frederiksen, Graversen, \& Smith, 2001). This may reflect that individuals with few hours in main occupation have to supplement their income with a second job in order to 
work the preferred hours, i.e., they are restricted from having a full-time job in their main occupation (see Trejo, 1993). At the other extreme, for individuals who hold both a full-time and a second job, the jobs often seem to be complements, i.e., professors with complementary consultancy jobs (see Paxson \& Sicherman, 1996). In these cases the second job may improve the career opportunities hence they are not accepted only to increase current wage income. This is a point which is discussed further in Section 5 .

The construction of individual budget constraints requires a specification of income both when the individuals are working and not working. The required information is obtained from different administrative registers (tax, income, social welfare and other income transfers, and UI-benefit registers), which have been merged to the survey information. Thus, we have information on total annual earnings, capital income and income from other sources, tax deductions, UI benefits, social welfare payments, child and housing subsidies.

The income when not working $\left(y_{0}\right)$ is calculated as follows: For individuals insured against unemployment (about $80 \%$ of the employees), we include potential unemployment benefits in the budget constraint. Unemployed individuals who are insured in an UI fund receive an hourly compensation of $90 \%$ of prior hourly wages up to a flat rate. The UI compensation in Denmark is independent of other sources of income and independent of the income of a spouse. In contrast to working individuals, we have no information on hourly wage rates for nonworking individuals. Hence, we use the predicted wage rate based on selectivity-corrected wage regressions to construct the budget constraint. ${ }^{9}$

About $5 \%$ of the individuals are observed as involuntarily unemployed, i.e., they are not working but have a desired positive labor supply according to the ILO criteria (cf. Table 2). Another group of the same size does not have a positive labor supply according to the ILO criteria. Both groups do not have an observed wage rate and for these individuals we use predicted hourly wage rates based on estimations of selectivity-corrected wage functions. Similar wage regressions are estimated for the missing wage rates on overtime and second jobs.

The sample includes married as well as single individuals. In the estimations, we model the individual labor supply decision, i.e., not a household decision. For married or cohabiting individuals we treat the spouse's net income after taxes and means-tested income transfers as exogenous nonlabor income. Thus, we only allow for an income effect between spouses' labor supply behavior and not a cross-substitution effect. 
Other Danish empirical studies find quite low cross substitution and family income effects between spouses (see Smith, 1995, among others). ${ }^{10}$

An overview of a number of demographic and regional variables used in the estimations is given together with sample means and deviations in Table A1 in the appendix.

\section{THE EMPIRICAL MODEL SPECIFICATION}

In order to specify the empirical model, we have to select a functional form of the labor supply function and a stochastic structure. In this study, we select a flexible nonlinear specification, which allows for backward bending labor supply as in Duncan (1993). The specification is nonlinear in the wage rates but linear in the nonlabor income. However, the direct utility function does not exist in a closed form, so instead we use the indirect utility function in the algorithm described above to find the desired labor supply. ${ }^{11}$

Consider the following empirical specification, which is linear in all the parameters to be estimated, $\theta$.

$$
h=f\left(w_{j}, y_{j}\right)=x_{j} \theta+v \equiv \hat{h}_{j}+v, \quad j=1, \ldots, k
$$

$\mathbf{x}_{j}$ is a vector of explanatory variables. The error component, $v$, represents heterogeneity in preferences with $v \sim N\left(\mu_{v}, \sigma_{v}^{2}\right)$ and it is assumed to be uncorrelated with observable variables in $\mathbf{x}_{j}$. The after-tax wage rate and virtual income enter the labor supply function by the nonlinear term $\beta \ln \left(w_{j}\right)+\gamma\left(y_{j} / w_{j}\right)$. This specification allows for a backward bending supply curve for some or all individuals if $\beta<0$ and $\gamma<0$. The model is well specified in a utility-maximizing sense as long as the Slutsky condition holds, i.e., $\left(\beta-\gamma\left(y_{j} / w_{j}\right)\right) / h-\gamma>0$ (cf. MaCurdy, Green, \& Paarsch, 1990).

Heterogeneity of preferences, represented by $v$, tends to generate clusters of observations around the convex kink points and to disperse observations away from nonconvex kink points (see Moffitt, 1986). The empirical data normally show no bunching or dispersion of individuals at or around the kink points, but usually there is a large concentration of observations at $h=0$ and at the standard number of hours in a full-time job $(37 \mathrm{~h}$ weekly in Denmark in 1996) which may reflect different constraints on labor supply or fixed costs of work in second job, as discussed in Section 2. In order to capture optimization errors or measurement errors, we add an additive random error term to the model. Let the observed labor supply, $h^{*}$, be a function of desired hours, $h$, and an error component, $\varepsilon$, so $h^{*}=h+\varepsilon$, where 
$\varepsilon \sim N\left(0, \sigma_{\varepsilon}^{2}\right)$ and $E(v, \varepsilon)=0$. Now the problem is that the observed $h^{*}$ is neither sufficient to allocate individuals to their correct budget segment nor sufficient to identify their marginal tax rate. Only the information on $h$ reveals this. Since the individuals' desired segment choice is not directly observable, one has a discrete-data version of an errors-in-variables problem, and the resulting stochastic model specification becomes the following:

$$
h^{*}=\left\{\begin{array}{lll}
H_{0}+\varepsilon & \text { if } \hat{h}_{1}+v \leq H_{0} & \text { Lower limit } \\
\hat{h}_{j}+v+\varepsilon & \text { if } H_{j-1}<\hat{h}_{j}+v \leq H_{j} & \text { Segment } j, j=1, \ldots, k \\
H_{j}+\varepsilon & \text { if } \hat{h}_{j+1}+v<H_{j}<\hat{h}_{j}+v & \text { Kink } j, j=1, \ldots, k-1 \\
H_{k}+\varepsilon & \text { if } \hat{h}_{k}+v \geq H_{k} & \text { Upper limit }
\end{array}\right.
$$

This combines the discrete and continuous parts of the choice in an estimable econometric model. The likelihood function becomes

$$
L=\prod_{i=I} G\left(h_{i}^{*}=0\right) \prod_{i=J} g\left(h_{i}^{*}\right) \prod_{i=K} G\left(h_{i}^{*}=H_{k}\right)
$$

where $G(\cdot)$ is the cumulative density function, and $g(\cdot)$, the derivative of $G(\cdot)$ w.r.t. $\mathbf{x}, \delta G(\cdot) / \delta x \cdot I$, the index set for the nonparticipants $\left(h^{*}=0\right), J$, the index set for the individuals with a positive labor supply less than $H_{k}$ $\left(0<h^{*}<H_{k}\right)$, and $K$ measures the individuals who work $H_{k}$ hours or more $\left(h^{*} \geq H_{k}\right)$. The exact expression of the density $g\left(h_{i}^{*}\right)$ and the probability $G\left(h_{i}^{*}=0\right)$ is given in the appendix. Maximization of the likelihood, $L$, provides point estimates of the parameters in the labor supply function. ${ }^{12}$

\section{BUDGET CONSTRAINTS AND MODEL SPECIFICATIONS}

In order to estimate the Hausman model, a complete specification of the budget constraint is required. For this reason, we will discuss the underlying assumptions which are necessary to construct the empirical budget constraints. The traditional Hausman model relies on the assumption that workers face one exogenously given wage, which is independent of the number of hours supplied. However, the empirical evidence presented in Tables 3 and 4 contradicts this assumption since a substantial part of the individuals are observed to work more than standard hours at overtime or 
second job wages, which often are different from the wage in the main occupation.

First, we propose models which follow the "hours constraints" specification (see models I-III below). These models assume (as discussed in Section 2) that labor supply at the main employer may be constrained and that institutional settings will distinguish hours supplied to the main job from overtime hours. Thus, underemployment in the main occupation and institutions may lead to overtime work and dual job holding. Further, these specifications assume that the disutility of work is similar across job types. These assumptions can be applied directly to the Danish case since collective agreements set standard hours to 37 per week and work beyond that at the main employer is considered overtime. Second, in model IV, we explore the "heterogeneous-job" specification by allowing the disutility of work to vary across jobs.

In model I, we estimate a "standard" Hausman model where the labor supply equals the sum of hours in main and second job plus overtime hours, but we ignore information on overtime payments and second job wage rates. This "baseline model" corresponds to the definitions of wage rates and working hours in Blomquist (1983) and Graversen (1998) and resembles many labor supply models estimated which have not explicitly focused on overtime work and second job information.

In model II, we add information on wages in second job and overtime payments. Thus, we improve the Hausman approach by allowing for a more realistic modeling of the labor supply decision. This will increase the marginal wage rates for most individuals working overtime and for some individuals in second job. Hence, other things being equal, the wage coefficient will increase together with the corresponding wage elasticity.

When including information of second job and overtime work, we have to impose a number of assumptions concerning behavior and outside restrictions in order to construct the budget constraint. First, we introduce the assumptions of "hours constraints": individuals supply overtime and second job hours because they are underemployed in main occupation and because institutions require main job hours to be distinguished from overtime hours. The disutility of work is assumed to be similar across jobs.

The budget constraint is easy to construct for employees working overtime but not in a second job. The reason is that collective agreements state that all work beyond $37 \mathrm{~h}$ per week at the main employer is overtime. Hence, when an employee works more than $37 \mathrm{~h}$ and receives an overtime premium, there will be a nonconvex kink at this point. When there is no overtime premium, the last main job segment is extended linearly as in the traditional Hausman model. 
Individuals working multiple jobs allocate most of their time (typically $37 \mathrm{~h}$ or more) to one of the jobs and only a few hours to the other (see Table 3). We use this observation to define an employee's main occupation as the job with most hours. Of course this assumption may be challenged by the few cases where the wage in the second job exceeds the main job wage but often these lucrative second jobs are only available to the individual conditional on holding the main job, i.e., professors working as consultants. Thus, this ordering of jobs seems natural.

Most employees who work more than standard hours have either a second job or they work overtime. However, a small group of individuals (about $1 \%$ according to Table 2 ) work both overtime and have a second job. In order to construct the budget constrains for these individuals we need to specify an ordering between these two types of jobs. We assume that overtime hours are preferred to a second job. There are at least two economic arguments supporting this assumption. First, on average overtime wages are empirically much higher than wages in a second job (see Table 4). Second, working in a second job is very likely to have additional fixed costs, i.e., transportation etc. which does not apply to overtime hours because these hours are an extension to the workday at the current employer. Thus, when an individual is observed to work in a second job, it is assumed that the overtime option has been exhausted.

Finally, we assume that individuals who are observed to work only in their main job can vary their labor supply as in the traditional Hausman model. If the individual is observed to have only a main job, there are in principle three alternative interpretations: (i) the individual may not have the option to work overtime or cannot find a second job; or (ii) he may have had, but not used, the option to become compensated for overtime work or the option of a second job where the wage exceeds the compensation in the main job; or (iii) he had the option of overtime work or second job, but at a salary which is too low. In case of (i), there may be institutional regulations preventing him from varying hours freely. In our model, this is captured by the error term $\varepsilon$. If (ii) applies, the budget constraint will have a nonconvex kink at observed hours. As a nonconvex kink cannot be an optimal allocation for the individual, it must be the case that the option of a higher compensation for overtime work or in a second job does not exist. Finally, in case (iii) the option of overtime payment at a lower wage level than in the main job can be ruled out because of institutional settings, while we cannot rule out the possibility of a convex kink because of the option of a second job with a lower net wage than in the main job. 
In model III, we introduce a more flexible specification related to the nonconvexity at $H_{0}$ due to the inclusion of UI benefits and social welfare. The nonconvexity forces the indifference curve to become very flat for individuals who are observed to work for instance in a fulltime job, in spite of the fact that their economic gain is quite low compared to being unemployed and receiving UI benefits, i.e., point $\left[H_{0}, y_{0}\right]$ in Fig. 1. This reflects that the economic disincentive problems are quite large in Denmark, see Pedersen and Smith (2002) who show that about $10 \%$ of all employees have a lower disposable income when working full time compared to being on UI benefits. In addition, the state as nonparticipant/voluntarily unemployed may imply a stigmatization effect for individuals who are unemployed and receive social welfare or UI benefits. The stigmatization may reflect that there is a negative effect on individual utility from being on public income support because of lower "reputation among neighbors" etc. Or, it may reflect that the individual is aware that being on public income support is a negative signal for a potential future employer. The stigmatization effect may also capture effects from administrative rules concerning availability for the labor market etc. In order to take these potential effects into account, we propose a more flexible specification where an indicator variable is added to the right-hand side of Eq. (3) for individuals who are observed working. ${ }^{13}$

Finally, in model IV we extend the model by including a "heterogeneousjob" effect. The disutility of work at the main employer may be different from the disutility of work in a second job. We implement this by adding a second indicator on the right-hand side of Eq. (3) for individuals who are observed to work in a second job. The second job dummy is intended to capture the discontinuity effects due to missing information on fixed costs (time and money costs of transportation and equipment) in second job as well as nonpecuniary benefits. We expect that adding this flexibility into the model may decrease the wage elasticity when the nonpecuniary benefits dominate since the number of hours and income in the second job in this case is less important and more likely a participation decision, i.e., a career or income improving action.

In sum, four versions of the labor supply model are estimated in order to evaluate how sensitive the estimation results are with respect to additional information on overtime payments and second job wage rates and the assumptions concerning the budget constraint. The strategy is successively to add more survey information and allow the model to be increasingly flexible. 


\section{EMPIRICAL RESULTS}

\subsection{The Hausman Model}

The empirical results are presented separately for men and women in Tables $5 \mathrm{a}$ and $5 \mathrm{~b}$. The key finding is that the detailed information on overtime payments and second job wages and the added flexibility of the Hausman model specification are important. First, the estimated wage and income coefficients are affected significantly. Second, the associated elasticities are

Table 5a. Estimation of Labor Supply Functions (Men 1996).

\begin{tabular}{|c|c|c|c|c|}
\hline & $\begin{array}{c}\text { I } \\
\text { Baseline }\end{array}$ & $\begin{array}{c}\text { II } \\
\text { Information on } \\
\text { Overtime and } \\
\text { Second Job }\end{array}$ & $\begin{array}{c}\text { III } \\
\text { II+Stigma } \\
\text { Effect }\end{array}$ & $\begin{array}{c}\text { IV } \\
\text { III+Second } \\
\text { Job Dummy }\end{array}$ \\
\hline $\ln \left(w_{\text {net }}\right) / 10$ & $0.736(0.143)$ & $1.281(0.142)$ & $0.333(0.080)$ & $0.169(0.039)$ \\
\hline$\left(y / w_{\text {net }}\right) / 100$ & $-0.079(0.029)$ & $-0.097(0.015)$ & $-0.016(0.003)$ & $-0.001(0.001)$ \\
\hline $\begin{array}{l}\text { Controls for } \\
\text { demographic } \\
\text { variables }\end{array}$ & Yes & Yes & Yes & Yes \\
\hline Stigma effect & - & - & $0.329(0.009)$ & $0.341(0.008)$ \\
\hline Second job dummy & - & - & - & $0.071(0.011)$ \\
\hline $\begin{array}{c}\sigma_{\varepsilon} \text { (measurement } \\
\text { optimization) }\end{array}$ & $0.090(0.002)$ & $0.097(0.001)$ & $0.046(0.002)$ & $0.024(0.001)$ \\
\hline$\sigma_{v}$ (heterogeneity) & $0.055(0.003)$ & $0.059(0.003)$ & $0.079(0.003)$ & $0.083(0.002$ \\
\hline $\log (L)$ & 904 & 877 & 1,034 & 1,195 \\
\hline Number of observations & 1,150 & 1,150 & 1,150 & 1,150 \\
\hline \multicolumn{5}{|l|}{ Elasticities $^{\mathrm{a}}$} \\
\hline$\varepsilon_{\text {ucw_net }}$ & $0.277(0.009)$ & $0.413(0.022)$ & $0.103(0.065)$ & $0.052(0.034)$ \\
\hline$\varepsilon_{\mathrm{CW} \_ \text {net }}$ & $0.358(0.010)$ & $0.496(0.022)$ & $0.119(0.063)$ & $0.053(0.034)$ \\
\hline$\varepsilon_{\mathrm{y}}$ & $-0.078(0.002)$ & $-0.143(0.021)$ & $-0.018(0.060)$ & $-0.006(0.023)$ \\
\hline
\end{tabular}

Note: The elasticities are calculated from the following expressions and evaluated at average sample values:

$$
\begin{aligned}
\varepsilon_{\mathrm{ucw}} & =\Phi\left(\frac{x \theta}{\sqrt{\sigma_{\epsilon}^{2}+\sigma_{v}^{2}}}\right)\left(\beta-\gamma \frac{y}{w}\right) \frac{1}{h}, \varepsilon_{y} \\
& =\Phi\left(\frac{x \theta}{\sqrt{\sigma_{\epsilon}^{2}+\sigma_{v}^{2}}}\right) \gamma \frac{y}{w h} \text {, and } \varepsilon_{\mathrm{cw}}=\varepsilon_{\mathrm{ucw}}-\frac{w h}{y} \varepsilon_{y} .
\end{aligned}
$$

${ }^{\text {a }}$ Dependent variable is weekly hours. Standard deviations in parentheses. 
Table 5b. Estimation of Labor Supply Functions (Women 1996).

\begin{tabular}{|c|c|c|c|c|}
\hline & $\begin{array}{c}\text { I } \\
\text { Baseline }\end{array}$ & $\begin{array}{c}\text { II } \\
\text { Information on } \\
\text { Overtime and } \\
\text { Second Job }\end{array}$ & $\begin{array}{c}\text { III } \\
\text { II+Stigma Effect }\end{array}$ & $\begin{array}{c}\text { IV } \\
\text { III+Second Job } \\
\text { Dummy }\end{array}$ \\
\hline $\ln \left(w_{\text {net }}\right) / 10$ & $1.111(0.245)$ & $3.326(0.175)$ & $0.363(0.130)$ & $0.488(0.093)$ \\
\hline$\left(y / w_{\text {net }}\right) / 100$ & $-0.022(0.014)$ & $-0.220(0.041)$ & $-0.032(0.022)$ & $-0.004(0.002)$ \\
\hline $\begin{array}{l}\text { Controls for } \\
\text { demographic } \\
\text { variables }\end{array}$ & Yes & Yes & Yes & Yes \\
\hline Stigma effect & - & - & $0.071(0.006)$ & $0.074(0.002)$ \\
\hline Second job dummy & - & - & - & $0.003(0.025)$ \\
\hline $\begin{array}{c}\sigma_{\varepsilon} \text { (measurement } \\
\text { optimization) }\end{array}$ & $0.115(0.002)$ & $0.065(0.001)$ & $0.032(0.022)$ & $0.030(0.001)$ \\
\hline$\sigma_{v}$ (heterogeneity) & $0.059(0.005)$ & $0.209(0.007)$ & $0.115(0.003)$ & $0.117(0.003)$ \\
\hline $\log (L)$ & 569 & 445 & 1,247 & 1,247 \\
\hline $\begin{array}{l}\text { Number of } \\
\text { observations }\end{array}$ & 1,291 & 1,291 & 1,291 & 1,291 \\
\hline \multicolumn{5}{|l|}{ Elasticities $^{\mathrm{a}}$} \\
\hline$\varepsilon_{\text {ucw_net }}$ & $0.360(0.005)$ & $0.760(0.019)$ & $0.137(0.034)$ & $0.148(0.038)$ \\
\hline$\varepsilon_{\mathrm{Cw} \text { net }}$ & $0.381(0.005)$ & $0.907(0.022)$ & $0.169(0.034)$ & $0.152(0.038)$ \\
\hline$\varepsilon_{\mathrm{y}}$ & $-0.040(0.001)$ & $-0.137(0.005)$ & $-0.030(0.025)$ & $-0.007(0.053)$ \\
\hline
\end{tabular}

Note: See Note in Table 5a.

${ }^{a}$ Dependent variable is weekly hours. Standard deviations in parentheses.

altered substantially. The estimated wage effect is significantly positive in all models while the income effect is negative, but often insignificant.

In the baseline model, model I, the estimated average wage elasticity (uncompensated elasticity of substitution) is 0.277 for men and 0.360 for women, while the average income elasticity is estimated to be -0.078 for men and -0.040 for women. ${ }^{14}$ This is in accordance with earlier Danish studies using the Hausman approach (see, for instance, Graversen, 1998). As expected from the literature, adding information on overtime and second job (model II) implies that the estimated wage elasticities increase considerably. The average uncompensated wage elasticity increases to 0.413 for men and 0.760 for women and the numerical size of the income effect also rises.

However, the numerically larger elasticities are reduced when we extend the traditional Hausman approach and allow for a more flexible treatment of nonconvexities in the budget constraint. In model III, we add the stigma effect which is intended to capture negative stigma or signaling effects from receiving public income transfers instead of income from work. This reduces the numerical size of the estimated coefficients and elasticities considerably. 
Adding the second job dummy (model IV) which controls for nonconvexities due to unobserved fixed costs or nonpecuniary benefits of second job reduces the size of the estimated coefficients for men even further. The estimated stigma effect in model III is high and it is quite stable when adding the second job dummy in model IV. Thus, the introduction of the flexibility terms into a traditional Hausman model seems to have large effects on the estimated coefficients and elasticities.

For women, nonconvexity due to stigma effects etc. are important, while nonconvexities due to second job only play a minor role. Both the stigma and the estimated second job effects are significant for men. This clearly indicates a career effect among men, but the effect seems to be absent among women. The more flexible specification used here compared to the traditional Hausman approach drives the estimated average wage elasticity for men from 0.41 to 0.10 (model III) and 0.05 (model IV), while for women the average wage elasticity drops from 0.76 to 0.14 (model III) and 0.15 (model IV). The average estimated income elasticities also reduce to an average close to 0 .

The size of the average elasticities found in the final model IV is lower than the results found in previous Danish studies using a Hausman approach (see Graversen, 1998). In a recent study using a nonparametric Hausman approach, Blomquist, Eklöf, and Newey (2001) have found wage elasticities for Swedish men of about 0.08 which is lower than earlier Swedish studies based on parametric Hausman models (see Blomquist \& Hansson-Brusewitz, 1990). In general, the elasticities estimated from model IV are positioned at the lower end of the scale compared to estimates from other studies using the Hausman method (see Blundell \& MaCurdy, 1999, for a survey).

The variance of both the measurement error and the heterogeneity error is significant in all specifications for both men and women except model III for women. Hence, the inclusion of the two error terms seems to be of importance. The size of the variance of the measurement and optimization error is approximately the double of the heterogeneity error variance in the baseline model I but it decreases the more information on overtime work and second job that is included in the models II, III, and IV, i.e., the more flexible the estimated model becomes.

\subsection{Alternative Model Specifications}

One question of particular interest is if the substantial variation in the parameters due to the inclusion of information on overtime and second job 
is unique to the Hausman model or if it can be observed in other model specifications as well. We explore this by estimating a set of linear regressions. In the first two models we only use wage information from the main job. Thus, we regress weekly hours on income and the wage in the main occupation (the marginal main job wage) ignoring overtime pay and second job wages. In the first model we use the gross wage, and in the second model the net wage. In the third model we include information on overtime and second job, which implies that the marginal net wage may include an overtime premium or be the net wage in a second job. There are other ways to use the additional information and the example provided here is only intended to illustrate the point that the estimated labor supply effects in a linear model are altered significantly when information on wages in overtime and second job is included.

We present the results from the linear regressions in Table 6. In the first model we find that the coefficient on the gross main job wage is positive and significant and the coefficient on income is negative for both men and women. Using the net wage instead changes the sign on the wage and reduces the coefficient on income to zero. Including information on overtime and second job alters the coefficient on the net wage significantly but recovers the negative significant sign on income. This implies that both the uncompensated wage elasticity of hours of work and the income effect are negative which resembles the early literature on labor supply reviewed by Pencavel (1986). Important in this context is that the presumption that the point estimates in the linear model are significantly altered when introducing information on overtime and second jobs is supported by the data. Hence, the result found in the Hausman model also applies to the linear framework.

Another important question is if the large variation in parameters is driven by the nonconvexities following the introduction of information on overtime and second job. One way to address this issue is to follow the work by MaCurdy et al. (1990) and "convexify" the budget set. Our model IV shows only minor deviations from the original results when the budget constraint is convexified as can be seen when the last two columns of Table 6 are compared with the results of Table 5. This suggests that it is not the treatment of the nonconvexity, i.e., how the applied algorithm allocates individuals to the optimal segment, but instead the introduction of additional information which is driving the results presented in this paper.

In the next section we analyze the effect of potential tax reforms using the results obtained from model specification IV since this model represents the most flexible specification and the highest likelihood value is obtained in this model. 


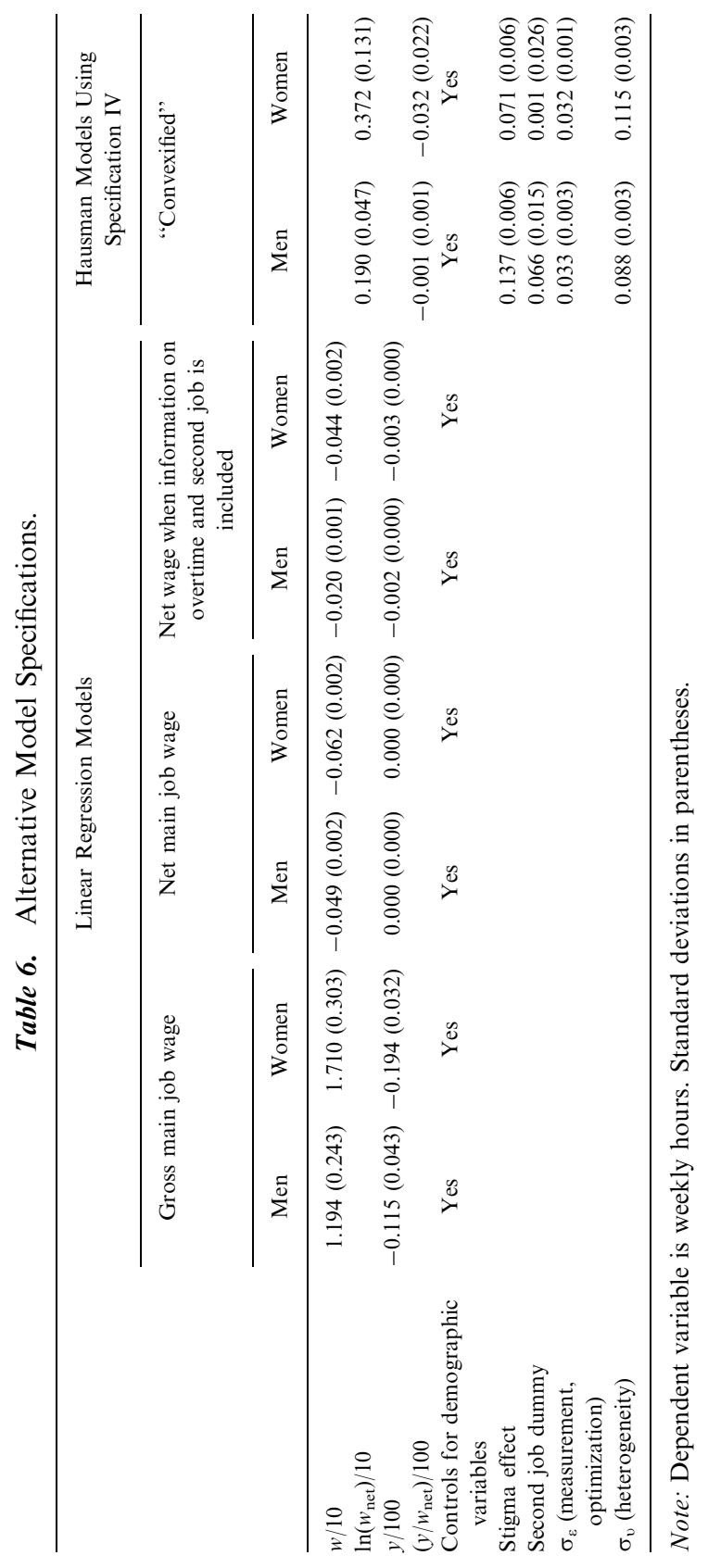




\section{LABOR SUPPLY RESPONSES TO TAX REFORMS}

In an analysis of the potential labor supply responses to a tax reform it is important to know the distribution of the substitution and income elasticities because it is the distributions and not the average elasticities which determine the degree of self-financing of a given tax reform. For this reason the sample distributions of the substitution and income elasticities for the preferred model (model IV) are shown in Fig. 2. The distributions of the uncompensated substitution elasticities are unimodal and fairly symmetric around the mean for both men and women, but with long tails and a higher mean for women. The distributions of income elasticities are slightly bimodal and more compressed for men than women (note that the scales on the axes are different for the distributions of income and substitution effects).

Four potential tax reforms are simulated. Reform A, B, and C (described below) each have an initial effect on public revenue corresponding to $1 \%$ of GDP, whereas reform D only affects initial revenue by $0.5 \%$. The reforms are chosen such that they will target different income brackets. The micro simulations are partial in the sense that they do not include general equilibrium effects and thus, the results from these simulations should be interpreted with care. Further, they are not modeled as budget-neutral reforms. ${ }^{15}$ In reform A, the upper income tax bracket (the "top tax") is removed (see Fig. 3). For the year 1996, this meant that the highest marginal tax rates were reduced from $65.8 \%$ to $51.8 \%$ for those with the highest incomes, about $20 \%$ of the sample according to Table 1 . In reform B, the marginal tax rates in segments three and four are reduced by about 4.5 percentage points (this corresponds to a removal of the so-called medium tax which is relevant for about $75 \%$ of the sample, according to Table 1). Reform $\mathrm{C}$ reduces the marginal tax rates for tax payers by 1.8 percentage points in segments $2-4$, which are relevant for more than $98 \%$ of the sample, according to Table 1. Compared to reform A, reform B and especially reform C imply much more moderate reductions of the highest tax rates, but for a much larger proportion of the population. In reform D, the kink point between the third and fourth tax segment is moved upwards, i.e., fewer tax payers face the highest marginal tax rate of $65.8 \%$. The coefficients from the final model IV in Tables $5 \mathrm{a}$ and $5 \mathrm{~b}$ are used in the prediction of labor supply responses. ${ }^{16}$

The revenue effects of the four tax reforms are described by the rate of self-financing, i.e., the tax revenue from increased labor supply as a percentage of the initial revenue loss due to the reform (see Table 7). These revenues differ substantially across the four reforms due to the large 
- Men

$\triangle$ Women

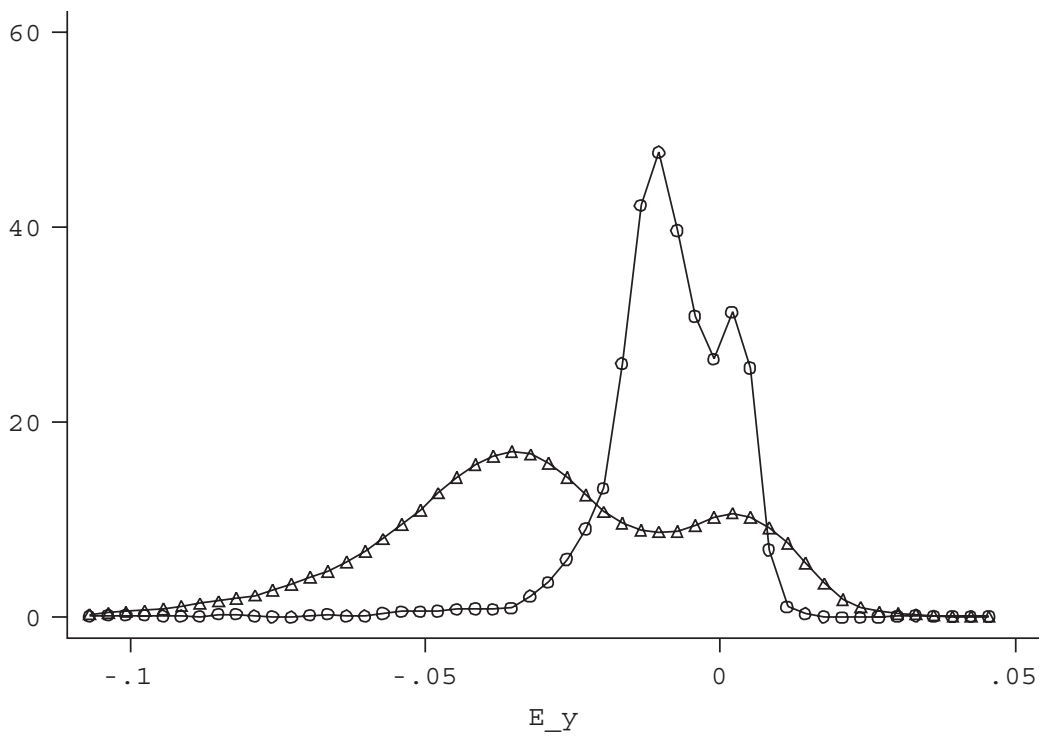

○ Men

$\triangle$ Women

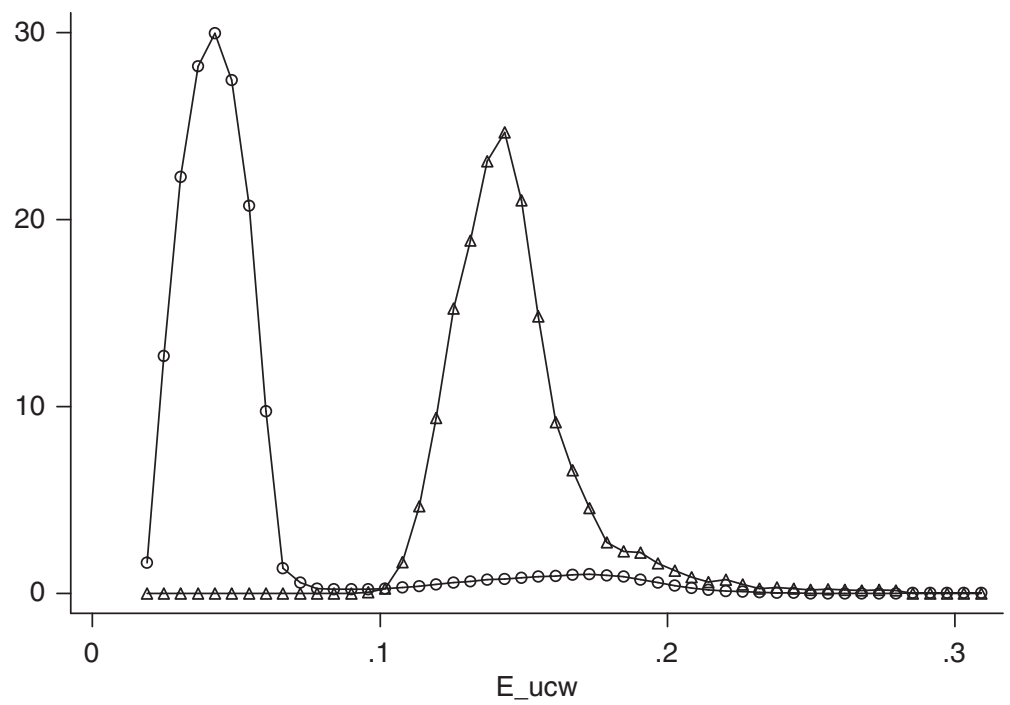

Fig. 2. Kernels for the Simulated Income and Substitution Elasticities. 

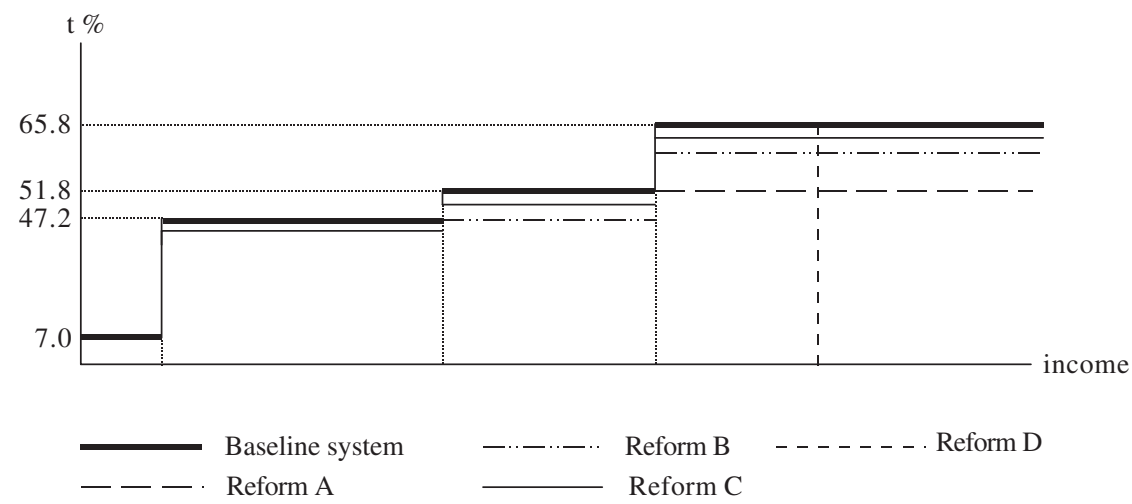

Fig. 3. The Danish Income Tax System in 1996 ("Baseline" System and Alternative Tax Reforms). Note: It is assumed that the person lives in a municipality with "average" tax rates, and that he does not have any positive or negative capital income or other income and no allowances beside the zero-rated allowance for local and state taxes.

Table 7. Public-Sector Revenue Effects Based on Alternative Hypothetical Tax Reforms ${ }^{\text {a }}$.

Public-Sector Revenue, Rate of Self-Financing

Reform A: Remove fourth segment (highest marginal tax rates 0.21 reduced from $65.8 \%$ to $51.8 \%$ )

Reform B: Remove third tax segment and lower marginal tax rates in highest tax segment (reduction of highest marginal tax rates by about $4.5 \%$ points in third and fourth tax segments)

Reform C: Reduce marginal tax rate in all tax segments by $1.8 \%$

Reform D: Shift third tax kink upwards (fewer pay the highest marginal tax rates)

\footnotetext{
${ }^{\mathrm{a}}$ Reforms A, B, and C have almost the same initial revenue effect (excl. labor supply effects) on public budgets, while the initial revenue effect of reform D is only about half of this effect. Simulations are based on the results from model IV.
} 
Table 8. Predicted Labor Supply and Public-Sector Revenue Effects Based on Alternative Model Specifications: Tax Reform A: Highest Marginal Tax Rates Reduced to $51.8 \%$ on Average.

\begin{tabular}{lcccc}
\hline & $\begin{array}{c}\text { I } \\
\text { Baseline }\end{array}$ & $\begin{array}{c}\text { II } \\
\text { Information on Overtime } \\
\text { and Second Job }\end{array}$ & $\begin{array}{c}\text { III } \\
\text { II+Stigma } \\
\text { Effect }\end{array}$ & $\begin{array}{c}\text { IV } \\
\text { III+Second Job } \\
\text { Dummy }\end{array}$ \\
\hline $\begin{array}{l}\text { Public-sector revenue, rate } \\
\text { of self-financing }\end{array}$ & 0.65 & 1.90 & 0.46 & 0.21 \\
$\begin{array}{l}\text { Labor supply effects (relative change of weekly hours) }(\%) \\
\text { Men }\end{array}$ & 2.2 & 7.0 & & \\
Women & 3.6 & 6.3 & 0.9 & 0.7 \\
\hline
\end{tabular}

variation in the labor supply responses. The proposed reforms have a rate of self-financing ranging from $12 \%$ for reform $\mathrm{C}$ to $58 \%$ for reform $\mathrm{D}$. A reduction of the marginal tax rates for virtually all tax payers (reform $\mathrm{C}$ ) will be fairly expensive for the public finances, while the dynamic effects from a moderate reform (D) which reduces the number of tax payers in the highest tax bracket will be relatively large and make this type of reform closer to being self-financing.

The predicted effects of the proposed tax reforms are known to be sensitive to the underlying econometric specification (see, for instance, Blundell \& MaCurdy, 1999). In order to analyze more closely the consequences for the results presented above, we have calculated the predicted labor supply responses and the rate of self-financing for reform $\mathrm{A}$ based on the four econometric specifications presented in Tables $5 \mathrm{a}$ and $5 \mathrm{~b}$ (see Table 8). ${ }^{17}$

The results show that the rates of self-financing are highly sensitive to the specification of the model. In general, the inclusion of detailed information on hours and wages in overtime work and second job and the added flexibility to the model reduce the labor supply effects of the tax reform compared to the results from a traditional labor supply "Hausman model."

\section{CONCLUSION}

In this paper, we have estimated labor supply functions for men and women in Denmark using a piecewise linear Hausman model to account for nonlinear taxes. We compare the estimated labor supply responses based on budget constraints reflecting detailed information on overtime work and second job with the traditional approach where information on overtime and second job 
wages is not taken into account. Our proposed extensions of the Hausman model give a more flexible and realistic modeling of the actual labor supply decision. A natural further extension would be to allow for joint household or family decisions which are not modeled explicitly in the present study.

Our main findings are that the results are highly sensitive to the specification and the flexibility of the labor supply model. The estimated average wage elasticities for men vary from 0.41 to 0.05 depending on specification and for women from 0.76 to 0.14 . The variation in estimated income elasticities is also relatively large. As found in previous studies the information on overtime payment and second job wages increases the numerical values of the estimated elasticities relative to a standard model which ignores this information. However, allowing for a more flexible treatment of the nonconvexities in the model specification, the numerical values of the estimated elasticities are reduced.

We analyze four hypothetical tax reforms, each targeting different income brackets. Since the estimated labor supply elasticities are fairly moderate, the tax cuts proposed are not fully self-financing through dynamic labor supply effects. The reform, closest to self-financing reduces the marginal tax rate for median income earners. The two reforms reducing the marginal tax rates for high-income earners or reducing the marginal tax rates for low-income earners (and hence for high-income earners too) are relatively expensive.

One of the main lessons from this study is that when analyzing the effects of tax reforms based on a Hausman-model approach, it is important to allow for sufficient flexibility at the nonconvex part of the budget constraints and to have as much information on the budget constraints as possible, i.e., information on overtime and second job wages. For the Danish tax system analyzed in this paper, the results indicate that strictly using a traditional Hausman approach may result in much too large estimates of the labor supply effects and hence incorrect predictions of the degrees of self-financing of tax reforms.

\section{NOTES}

1. See, for example, Aaberge, Colombino, and Strom (1999), van Soest (1995), and Hart (2004) for a discussion of the free choice of work hours or rather work packages, and Paxson and Sicherman (1996) and Frederiksen, Graversen, and Smith (2005) for a discussion of the dual job holder characteristics.

2. Contrary to papers like Blomquist (1983) and Flood and MaCurdy (1992), our male sample is not restricted to workers with positive hours, but we allow the small group of nonworking men to influence the results. 
3. The ambition in this study is to analyze the sensitivity of the Hausman approach to more flexible specifications and additional information on overtime and second job. An alternative approach to the Hausman model is a choice-based model such as the random utility model (see for instance Aaberge, Colombino, \& Strom, 2004). Choice-based models may provide complementary information on how variation in relative wages across different types of jobs affects the composition of labor supply.

4. See Averett and Hotchkiss (1997) for a discussion of the exogeneity of the budget constraint in the context of the part-time/full-time labor supply decision.

5. A third approach is to see dual job holding as an insurance against unemployment. There are two reasons why we ignore this hypothesis. First, the existing empirical evidence based on a study of the British Household Panel provides only weak evidence for the hypothesis (see Bell, Hart, \& Wright, 1997). Second, the high unemployment benefits level in Denmark suggests that the insurance argument is unlikely to be the main motivation for dual job holding in the present study.

6. The Danish UI-benefit rules allow a person to insure either as a part-time worker or as a full-time worker. If insured as a part-time worker, the insurance premium and the UI benefits in case of unemployment are lower than if full-time insured.

7. It may be criticized that the time dimension is not the same for overtime work, second job, and work in main occupation. We prefer to use "the normal work hours" as a measure of the labor supply since it gives a smoothed measure of the desired labor supply. Unfortunately, this information for overtime hours is not available in our data set. Instead, we use the "best" approximation available.

8. The incidence of overtime in Denmark seems to be considerably lower than in the UK where overtime incidence (for males) is found to be about $40 \%$ (see Kalwij \& Gregory, 2005). For the US, Trejo (1993) finds that the dual-job-holding rate is about $6 \%$ for both men and women in the 1991 CPS sample which is based on observations in a given survey week. When using annual data, the dual-job-holding rate is considerably higher, $21 \%$ for men and $12 \%$ for women. Similarly, Paxson and Sicherman (1996) find rates on $20 \%$ and $12 \%$ based on US PSID data for 1976-1989 for men and women separately. Since our data are based on a question on "normal weekly hours in second job," the larger figures are probably the relevant figures to compare.

9. Three selectivity-corrected wage regressions are used in this study: main occupation, overtime work, and second job. Similar to Blomquist and HanssonBrusewitz (1990), we estimate a wage rate function on the subgroup with observable wage rates, taking account of sample selection bias by a Heckman procedure. Identification is secured by including additional survey and register information on demographic variables etc. (child variables, information on marriage or cohabitation, and ownership of house) in the participation relation, and information on tenure, occupational level, and regional variables in the wage function. Subsequently, the regression results are used to predict wages. All wage functions are available from the authors upon request.

10. Aaberge et al. $(1999,2004)$ also find low cross-substitution effects among middle class and especially among rich households. Similarly, van Soest (1995) finds low cross-substitution effects and low family income effects on Dutch data. Thus, we do not expect that this shortcoming of our approach will seriously bias the results. 
11. As an alternative, we have used the linear labor supply specification, which was also used in Blomquist (1983) and Flood and MaCurdy (1992). It is linear in both wage rates and nonlabor income, and the direct utility function has an explicit closed form. Contrary to the results found in other studies, we do not find, that the results (measured by average elasticities for different demographic groups) are very sensitive to choice of specification (see Sacklén, 1996). Since the nonlinear specification is the more flexible and since it performs statistically slightly better, we present the results from the nonlinear specification.

12. The sample used is a nonrepresentative sample where unemployed persons are over-sampled. Therefore, the likelihood function in Eq. (5) is weighted by the appropriate weights.

13. Another way to obtain something similar would be to exclude the nonworking individuals.

14. The elasticities are calculated for each individual in the sample according to Note below Table 5a. The average of theses elasticities are presented in the text and tables.

15. It should be mentioned that the analysis is also partial in the sense that we do not include dynamic effects, i.e., potential effects on consumption and indirect tax revenues. If these effects are included, the rate of self-financing of the tax reforms analyzed above will increase, since disposal income will increase for all income groups. The potential effects of taxation on the wage formation process are not included either (see for instance Bingley \& Lanot, 2002).

16. The labor supply response to a given tax reform is determined as the difference in predicted pre- and postreform labor supply.

17. We only present the results from reform A since it is exactly the same pattern of variation which appears for all the reforms analyzed in Table 7.

\section{ACKNOWLEDGMENT}

The data set used in this study was created and financed by the Rockwool Research Foundation which has also partly financed the research project. The presented analysis is solely the authors' responsibility.

\section{REFERENCES}

Aaberge, R., Colombino, U., \& Strom, S. (1999). Labour supply in Italy: An empirical analysis of joint household decisions, with taxes and quantity constraints. Journal of Applied Econometrics, 14, 403-422.

Aaberge, R., Colombino, U., \& Strom, S. (2004). Do more equal slices shrink the cake? An empirical investigation of tax-transfer reform proposals in Italy. Journal of Population Economics, 17(4), 767-785.

Arrufat, J., \& Zabalza, A. (1986). Female labor supply with taxation, random preferences, and optimization errors. Econometrica, 54(1), 47-63. 
Ashworth, J., \& Ulph, D. (1981). Endogeneity I, estimating labor supply with piecewise linear budget constraints. In: C. V. Brown (Ed.), Taxation and labor supply. London, UK: Allen \& Unwin Chap 6.

Averett, S. L., \& Hotchkiss, J. L. (1997). Female labour supply with a discontinuous, nonconvex budget constraint: incorporation of a part-time/full-time wage differential. Review of Economics and Statistics, 79, 461-470.

Bell, D., Hart, R. A., \& Wright, R. E. (1997). Multiple job holding as a 'hedge' against unemployment. CEPR Discussion Paper No. 1626.

Bingley, P., \& Lanot, G. (2002). The incidence of income tax on wages and labour supply. Journal of Public Economics, 83(2), 173-194.

Bingley, P., \& Walker, I. (2001). Household unemployment and the labour supply of married women. Economica, 68(270), 157-185.

Blomquist, S. (1983). The effect of income taxation on the labor supply of married men in Sweden. Journal of Public Economics, 22, 169-197.

Blomquist, S., Eklöf, M., \& Newey, W. (2001). Tax reform evaluation using non-parametric methods: Sweden 1980-1991. Journal of Public Economics, 79, 543-568.

Blomquist, S., \& Hansson-Brusewitz, U. (1990). The effect of taxes on male and female labour supply in Sweden. Journal of Human Resources, 25, 317-357.

Blundell, R., \& MaCurdy, T. (1999). Labor supply: A review of alternative approaches (Chap. 27). In: O. Ashenfelter \& D. Card (Eds), Handbook of labor economics. Amsterdam: Elsevier.

Conway, K. S., \& Kimmel, J. (1998). Male labor supply estimates and the decision to moonlight. Labour Economics, 5, 135-166.

Duncan, A. (1993). Labour supply decisions and non-convex budget sets: The case of National Insurance Contribution in the UK. In: A. Heimler \& D. Meulders (Eds), Empirical approaches to fiscal policy. London: Chapman and Hall.

Euwals, R., \& van Soest, A. (1999). Desired and actual labour supply of unmarried men and women in the Netherlands. Labour Economics, 6(1), 95-118.

Flood, L., \& MaCurdy, T. (1992). Work disincentive effects of taxes: An empirical analysis of Swedish men. Carnegie-Rochester Conference Series on Public Policy, 37, 239-278.

Frederiksen, A., Graversen, E., \& Smith, N. (2001). Overtime work, dual job holding and taxation. IZA Discussion Paper No. 323, Forschungsinstitut zur Zukunft der Arbeit, Bonn.

Frederiksen, A., Graversen, E., \& Smith, N. (2005). Tax evasion and work in the underground sector. Labour Economics, 12(5), 613-628.

Graversen, E. (1998). Labour supply and work incentives. PhD thesis 1998-2002, University of Aarhus, Aarhus.

Hart, R. A. (2004). The economics of overtime working. Cambridge, UK: Cambridge University Press.

Heineck, G. \& Schwarze, J. (2004). Fly me to the moon: The determinants of secondary jobholding in Germany and the UK. IZA Discussion Paper. No 1358.

Kalwij, A. S., \& Gregory, M. (2005). Overtime hours in Great Britain over the period 1975-1999: A panel data analysis. Journal of the Royal Statistical Society, Series A, 168(1), 207-231.

MaCurdy, T., Green, D., \& Paarsch, H. (1990). Assessing empirical approaches for analyzing taxes and labor supply. The Journal of Human Resources, XXV(3), 415-490.

Moffitt, R. (1986). The econometrics of piecewise-linear budget constraints. A survey and exposition of the maximum likelihood method. Journal of Business and Economic Statistics, 4(2), 317-328. 
OECD. (1996). Employment outlook, Paris

Paxson, C. H., \& Sicherman, N. (1996). The dynamics of dual job holding and job mobility. Journal of Labor Economics, 14(3), 357-393.

Pedersen, P., \& Smith, N. (2002). Unemployment traps and financial disincentives to work. European Sociological Review, 18(3), 271-288.

Pencavel, J. (1986). Labor supply of men: A survey (Chap. 1). In: O. Ashenfelter \& R. Layard (Eds), Handbook of labor economics. Amsterdam: Elsevier.

Sacklén, H. (1996). Essays on Empirical Models of Labor Supply: Economic Studies (Vol. 27). Uppsala: Department of Economics, Uppsala University.

Shisko, R., \& Rostker, B. (1976). The economics of multiple job holding. American Economic Review, 66(3), 298-308.

Smith, N. (1995). A panel study of labour supply and taxes in Denmark. Applied Economics, 27, 419-429.

Smith, N. (1998). Arbejde, incitamenter og ledighed (In Danish). Aarhus: The Rockwool Foundation Research Unit and Aarhus Universitetsforlag.

Smith, N., Dex, S., Vlasblom, J. D., \& Callan, T. (2003). The effects of taxation on married women's labour supply across four countries. Oxford Economic Papers, 55(3), 417-439.

Trejo, S. J. (1993). Overtime pay, overtime hours, and labor unions. Journal of Labor Economics, 11(2), 253-278.

van Soest, A. (1995). Structural models of family labor supply: A discrete choice approach. The Journal of Human Resources, 30(1), 63-88.

\section{APPENDIX}

\section{The Likelihood Function}

The probability $G\left(h_{i}^{*}=0\right)$ can be written as

$$
\begin{aligned}
& G\left(h_{i}^{*}=0\right) \\
&=\int_{-\infty}^{-H_{0 i}} \int_{-\infty}^{H_{0 i}-\hat{h}_{l i}} \varphi_{1}\left[h_{i}^{*}-H_{0}, v_{i}\right] \mathrm{d} v_{i} \mathrm{~d} \varepsilon_{i} \quad \text { Lower limit } \\
&+\sum_{j=1}^{k} \int_{-\infty}^{-\hat{h}_{j i}} \int_{H_{(j-1) i}-\hat{h}_{j i}}^{H_{j i}-\hat{h}_{j i}} \varphi_{2}\left[h_{i}^{*}-\hat{h}_{j i}, v_{i}\right] \mathrm{d} v_{i} \mathrm{~d} \varepsilon_{i} \quad \text { Segment } j, j=1, \ldots, k \\
&+\sum_{j=1}^{k-1} \int_{-\infty}^{-H_{j i}} \int_{H_{j i}-\hat{h}_{j i}}^{H_{j i}-\hat{h}_{(j+1) i}} \varphi_{1}\left[h_{i}^{*}-H_{j i}, v_{i}\right] \mathrm{d} v_{i} \mathrm{~d} \varepsilon_{i} \quad \text { Kink } j, j=1, \ldots, k-1 \\
&+\int_{-\infty}^{-H_{k i}} \int_{H_{k i}-\hat{h}_{k i}}^{\infty} \varphi_{1}\left[h_{i}^{*}-H_{k}, v_{i}\right] \mathrm{d} v_{i} \mathrm{~d} \varepsilon_{i} \quad \text { Upper limit }
\end{aligned}
$$


and the density $g\left(h_{i}^{*}\right)$ can be written as

$$
\begin{aligned}
g\left(h_{i}^{*}\right) & =\int_{-\infty}^{H_{0 i}-\hat{h}_{0 i}} \varphi_{1}\left[h_{i}^{*}-H_{0}, v_{i}\right] \mathrm{d} v_{i} \quad \text { Lower limit } \\
& +\sum_{j=1}^{k} \int_{H_{(j-1) i}-\hat{h}_{j i}}^{H_{j i}-\hat{h}_{j i}} \varphi_{2}\left[h_{i}^{*}-\hat{h}_{j i}, v_{i}\right] \mathrm{d} v_{i} \quad \text { Segment } j, j=1, \ldots, k \\
& +\sum_{j=1}^{k-1} \int_{H_{j i}-\hat{h}_{j i}}^{H_{j i}-\hat{h}_{(j+1) i}} \varphi_{1}\left[h_{i}^{*}-H_{j i}, v_{i}\right] \mathrm{d} v_{i} \quad \text { Kink } j, j=1, \ldots, k-1 \\
& +\int_{H_{k i}-\hat{h}_{k i}}^{\infty} \varphi_{1}\left[h_{i}^{*}-H_{k}, v_{i}\right] \mathrm{d} v_{i} \quad \text { Upper limit }
\end{aligned}
$$

There are no individuals with $h_{i}^{*}=H_{k}$. Hence, $G\left(h_{i}^{*}=H_{k}\right)$ is not in the likelihood we maximize. Arrufat and Zabalza (1986) give expressions for both $G(\cdot)$ and $g(\cdot) . \Phi_{1}(\cdot, \cdot)$ and $\Phi_{2}(\cdot, \cdot)$ are bivariate normal density functions of $(\varepsilon, v)$ and $(\varepsilon+v, v)$ with means, variances, and covariance $\left(0,0, \sigma_{\varepsilon}^{2}, \sigma_{v}^{2}, 0\right)$ and $\left(0,0, \sigma_{\varepsilon}^{2}+\sigma_{v}^{2}, \sigma_{v}^{2}, \sigma_{v}^{2}\right)$, respectively. There is no a priori reason to expect the heterogeneity and measurement errors to be correlated.

\begin{tabular}{|c|c|c|c|c|}
\hline \multirow[t]{2}{*}{ Variable } & \multicolumn{2}{|r|}{ Men } & \multicolumn{2}{|r|}{ Women } \\
\hline & Mean & Standard deviation & Mean & Standard deviation \\
\hline \multicolumn{5}{|c|}{ Weekly labor supply, given participation } \\
\hline Main occupation & 37.9 & 5.0 & 34.5 & 6.5 \\
\hline Overtime work & 2.1 & 5.1 & 1.0 & 2.8 \\
\hline Second job & 1.0 & 4.3 & 0.4 & 2.2 \\
\hline \multicolumn{5}{|c|}{ Hourly gross wage rate, DKK } \\
\hline Main occupation & 133.7 & 53.8 & 107.0 & 26.9 \\
\hline Overtime work & 170.1 & 53.3 & 148.6 & 66.1 \\
\hline Second job & 140.5 & 110.6 & 135.9 & 126.9 \\
\hline $\begin{array}{l}\text { Weekly nonlabor income, } \\
\text { DKK }\end{array}$ & $2,725.4$ & $1,401.3$ & $3,170.3$ & $1,439.9$ \\
\hline Marginal tax rate $(\%)$ & 54.7 & 13.1 & 48.0 & 15.2 \\
\hline Age & 39.1 & 11.1 & 39.1 & 10.4 \\
\hline Owner of house $(0 / 1)$ & 0.64 & 0.49 & 0.69 & 0.46 \\
\hline
\end{tabular}
Hence, we assume no correlation as almost all other studies in the area (cf. Moffitt, 1986).

Table A1. Descriptive Statistics. 
Table A1. (Continued)

\begin{tabular}{lccccc}
\hline \multirow{2}{*}{ Variable } & \multicolumn{2}{c}{ Men } & & \multicolumn{2}{c}{ Women } \\
\cline { 2 - 3 } \cline { 5 - 6 } \cline { 5 - 6 } & Mean & Standard deviation & & Mean & Standard deviation \\
\hline Region & 0.30 & & & & \\
$\quad$ Copenhagen & 0.34 & 0.46 & & 0.32 & 0.46 \\
$\quad$ Major cities & 0.36 & 0.49 & & 0.32 & 0.46 \\
$\quad$ Country & 0.13 & 0.34 & & 0.15 & 0.47 \\
Children 0-2 years (0/1) & 0.11 & 0.33 & & 0.11 & 0.35 \\
Children 3-6 years (0/1) & 0.75 & 0.96 & & 0.85 & 0.32 \\
Number of children & & & & 0.95 \\
Civil state & 0.24 & 0.42 & & 0.22 & 0.41 \\
$\quad$ Single & 0.58 & 0.50 & & 0.62 & 0.48 \\
$\quad$ Married & 0.18 & 0.39 & & 0.16 & 0.37 \\
$\quad$ Cohabiting & & 1,150 & & & 1,291 \\
Number of observations & & & & & \\
\hline
\end{tabular}

